\title{
Testosterone Undecanoate
}

National Cancer Institute

\section{Source}

National Cancer Institute. Testosterone Undecanoate. NCI Thesaurus. Code C1249.

The undecanoate ester form of the androgen testosterone, with gonadotropinsecretory inhibiting and hormone replacement activity. As testosterone inhibits the secretion of gonadotropins from the pituitary gland, administration of testosterone decreases the secretion of luteinizing hormone (LH). By inhibiting LH secretion, the growth of Leydig cells, which are normally stimulated by LH to produce testosterone, may be suppressed. In addition, this agent promotes the maintenance of male sex characteristics and can be used for testosterone replacement in hypogonadal males. 